\title{
Integration between electric heat pump and PV system to increase self-consumption of an office application
}

\author{
Carlo Roselli*, Maurizio Sasso, and Francesco Tariello \\ Dipartimento di Ingegneria, Università Degli Studi Del Sannio, Piazza Roma 21, Benevento, Italy
}

Received: 28 February 2017 / Received in final form: 10 July 2017 / Accepted: 27 July 2017

\begin{abstract}
The paper examines a solar electric driven heat pump serving an office building located in southern Italy. To satisfy space heating and cooling demand a heat pump activated by electric energy available from solar photovoltaic plant is here considered. In order to improve the self-consumption of electricity available from photovoltaic system different configurations were considered introducing an electric storage and an electric vehicle. Dynamic simulations to evaluate energy performance of the system varying photovoltaic peak power $(4.5-7.5 \mathrm{~kW})$ have been carried out. The proposed system achieves a fossil fuel primary energy saving up to about $96 \%$ in comparison to the reference conventional system based on a natural gas fired boiler, an electric chiller and the national electric grid. The results show that fossil fuel primary energy saving is higher when there are no storage battery and electric vehicle.
\end{abstract}

\section{Introduction}

In European Union in 2012 about 295 Mtoe corresponding to $27 \%$ of final energy consumption are due to space heating and cooling demand representing one of the largest energy sector [1]. In Italy primary energy requirements for space heating and cooling in residential and tertiary sectors achieved in 2013 about 39 Mtoe corresponding to about $79 \%$ of the total primary energy demand [2]. These data have determined an increasing interest in the technologies able to reduce primary energy consumption and greenhouse gas emissions in the residential and tertiary sectors due to typical energy demands (space heating and cooling, domestic hot water) of a building.

Different paths could be followed to achieve these goals and in the last years great attention was generated by renewable-based plants and in particular on solar heating and cooling (SHC) systems. Among them strong efforts were focused on thermally-activated refrigeration devices [3] such as adsorption [4] and absorption heat pumps [5], evaporative and ejector cooling systems [6], HVAC (heating and ventilation air conditioning) desiccant-based air handling unit [7]. These systems, compared with fossil fuel-based energy conversion systems, can reach a primary energy saving up to $67 \%$ [8], even if investment costs are too high to make these technologies interesting for the actual market [9]. A different way to use solar energy for heating and cooling purpose is the introduction of a photovoltaic

\footnotetext{
* e-mail: carlo.roselli@unisannio.it
}

system interacting with an electric heat pump (EHP). Until 2015 in Italy a cumulative peak power of $18.9 \mathrm{GW}$ of photovoltaic (PV) panels was installed. These PV systems deliver on yearly basis up to $22.9 \mathrm{GWh}$ of electric energy, corresponding to $8.4 \%$ of total Italian electricity demand [10]. Only $18.6 \%$ of electric energy available from PV was self-consumed, while the remaining part feeds the national grid [11].

These data led to an increasing interest in technologies able to increase the self-consumption of electricity that appears too low. High energy demand for space heating and cooling in the residential and tertiary sectors and also the local availability of electric energy from PV has determined in Italy an increasing interest in the introduction of electric heat pump to increase the self-consumption of electricity. To further increase the self-consumption of electricity it could be interesting to add to solar electric heating and cooling plant a stationary electric storage, located next to the building, or a mobile one considering an electric vehicle.

Solar electric heating and cooling plant based on a PV plant and an EHP [12] satisfying electric, thermal and cooling demand of an office building located in southern Italy was analyzed. Dynamic simulations to evaluate energy, environmental and economic performance of the proposed system, varying PV peak powers, tilt angles, electricity and natural gas unit prices, are carried out by means of TRNSYS software. The solar-based system shows a saving in terms of primary energy due to fossil fuel and equivalent $\mathrm{CO}_{2}$ emission reduction up to about $81 \%$ if compared to the reference conventional system based on a boiler fueled by natural gas and an electric-driven chiller. 
Table 1. Main data of building envelope.

Transmittance $\left(\mathrm{W} / \mathrm{m}^{2} \mathrm{~K}\right)$ Thermal mass $g$-Value $(-)$ $\left(\mathrm{kg} / \mathrm{m}^{2}\right)$

\begin{tabular}{lll}
\hline Window 2.58 & - & 0.75 \\
External0.40 & 373 & - \\
wall & & \\
Roof 0.38 & 322 & - \\
Ground 0.42 & 689 & - \\
\hline
\end{tabular}

A comparison between solar thermal and solar electric cooling systems for a typical small office building in two different European locations (Freiburg, Germany and Madrid, Spain) by means of TRNSYS was performed by Hartmann et al. [13]. The authors investigate, varying solar collecting area, the performance of the systems on the basis of energy and economic indices. Large collector areas lead up to $40 \%$ for Freiburg and $60 \%$ for Madrid of primary energy saving both for solar thermal and PV based.

To satisfy space heating and cooling demand of an office building a heat pump activated by electric energy available from solar photovoltaic plant equipped with an electric storage is considered by Roselli et al. [14]. Thermoeconomic analysis varying PV peak power and electric battery capacity is carried out through TRNSYS. In comparison to the reference conventional system based on a natural gas fired boiler and an electric chiller a fossil fuel primary energy saving and an equivalent dioxide carbon emission reduction up to about $82 \%$ is achieved by solarbased system.

Spanish researchers [15] perform a theoretical and experimental analysis of an air to water electric heat pump interacting with a solar system based on PV panels with a peak power of $2.88 \mathrm{~kW}$ and electric storage with a capacity of $250 \mathrm{Ah}$. The heat pump, with a nominal thermal power of $6 \mathrm{~kW}$, heats a laboratory, located in Spain, supplying hot water to radiant floor.

Roselli and Sasso [16], analyze the introduction of a PV system satisfying electric, space heating and cooling demand of an office building located in Southern Italy. The electric load is due to an EHP, used to satisfy space heating and cooling load, pure electric demand (personal computer, printers, lighting, etc.) and an electric vehicle (EV) charged during working hours. Dynamic simulations to evaluate the energy and environmental performance of the analyzed system considering different PV peak power, electric vehicle distance per day and charging mode is carried out. The solar based system shows a fossil fuel primary energy saving and equivalent carbon dioxide emission reduction higher than $40 \%$ in comparison to the reference conventional system based on a natural gas fired boiler, an electric chiller and a diesel car.

The previous literature survey showed that existing works deal with simulative or experimental analysis of SHC systems based on electric heat pump interacting with a PV field. In this paper a PV plant interacting with an EHP that satisfies space heating and cooling demand of an office building located in southern Italy is considered on annual basis in terms of energy analysis. The analysis is performed considering three configurations: the first one based only on $\mathrm{PV} / \mathrm{EHP}$ system, the second one integrates also an electric storage and the third one includes a charging station for $\mathrm{EV}$. The aim of introduction of stationary and mobile (EV) batteries is the increase of self-consumption of electricity available from PV system that could lead to a reduction of the problems (power quality, load managing, etc.) due to electricity exported to the grid by means of small scale renewable-based distributed power systems.

\section{Building and user description}

This paper deals with an office building with a flat roof, one floor, $200 \mathrm{~m}^{2}, 600 \mathrm{~m}^{3}$ with 13 working persons. Terminal units used to meet space heating and cooling requirements are fan-coils. The occupancy during weekdays is 9:00-14:00 and 15:00-18:00, while the office is unused in the weekends. Seated persons with very light working as degree of activity are here considered. The office is located in Naples (1034 heating degree days; $40^{\circ} 51 / 11.8584 / \prime \mathrm{N}$ ) and the characteristics of the building envelope are reported in Table 1 . The domestic hot water demand with respect to the heating demand is considered negligible. According to Italian legislation restraints the heating system is active between November 15 and March 31 . Heating system operates during weekdays between 8:00 and 18:00 and the air temperature room set-point is $20.0^{\circ} \mathrm{C}\left( \pm 0.5^{\circ} \mathrm{C}\right)$, while the heating system is turned off in the weekends. The cooling system operates between June 1 and September 30 with equivalent occupancy and internal gain introduced for heating period, while set-point temperature is $26.0^{\circ} \mathrm{C}\left( \pm 0.5^{\circ} \mathrm{C}\right)$. Energy demand for space heating achieves on yearly basis $2920 \mathrm{kWh}$ with unitary requirements of $14.6 \mathrm{kWh} / \mathrm{m}^{2}$ and $4.87 \mathrm{kWh} /$ $\mathrm{m}^{3}$. Space cooling energy requirement is $6453 \mathrm{kWh} /$ year with unitary demand equal to $32.3 \mathrm{kWh} / \mathrm{m}^{2}$ and $10.7 \mathrm{kWh} / \mathrm{m}^{3}$. The electric demand, excluding HVAC requirements, is assumed equal to $27.9 \mathrm{kWh} / \mathrm{m}^{2}$ per year for small power equipment in office buildings (PC, monitor, printers, etc.) and $12.5 \mathrm{kWh} / \mathrm{m}^{2}$ annum for artificial lights according to onsite analysis performed on electricity consumption in office buildings [17].

The electric load profile, without including HVAC requirements, Figure 1, is defined for three type days (heating, cooling and intermediate) considering weekday demands, while there is only one type day for weekend demand.

A further analysis is based on the introduction of a further electric load due to an EV charged during working hours for proposed system and a diesel vehicle for traditional system. In both the systems the car covers $120 \mathrm{~km} /$ day during weekday for a total of $31200 \mathrm{~km}$ on yearly basis.

\section{System components}

To satisfy heating and cooling load of the office a solar electric driven heat pump is here considered as proposed system (PS). The energy conversion system is based on a PV field, an inverter, and an EHP. The PV system covers 


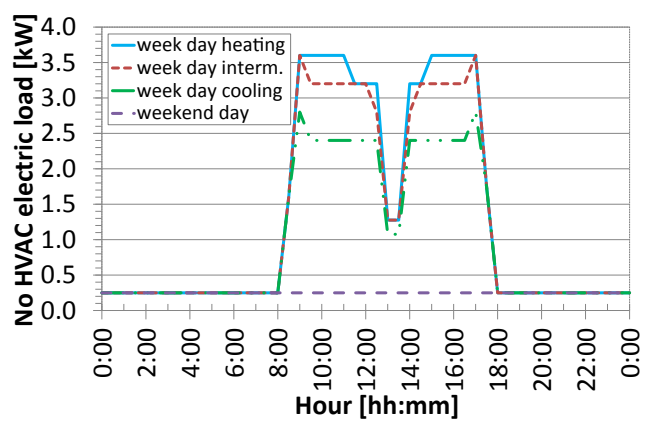

Fig. 1. Electric load excluding HVAC.
Table 2. PV characteristics at standard test conditions (STC). ${ }^{\mathrm{a}}$

Max. power $(\mathrm{kW})$

0.25

Solar panel electric efficiency $(\%)$

15.28

Maximum power voltage $(\mathrm{V})$

30.38

Maximum power current (A)

8.29

Open circuit voltage, $V_{o c}(\mathrm{~V})$

37.12

Short circuit current, $I_{s c}(\mathrm{~A})$

8.76

Maximum power temperature factor $(\% / \mathrm{K}) \quad-0.42$

Temperature coefficient for $V_{o c}(\% / \mathrm{K})$

$-0.32$

Temperature coefficient for $I_{s c}(\% / \mathrm{K})$

0.059

Gross area $\left(\mathrm{m}^{2}\right)$

1.64

${ }^{a}$ Standard test conditions: air mass 1.5 ; irradiance equal to $1.0 \mathrm{~kW} / \mathrm{m}^{2}$; cell temperature equal to $25^{\circ} \mathrm{C}$.

Table 3. Inverter characteristics.

\begin{tabular}{lccc}
\hline Rated DC input power (kW) & 5.15 & 6.20 & 7.65 \\
Rated AC power (kW) & 5.00 & 6.00 & 7.50 \\
MPPT number (-) & 2 & 2 & 2 \\
Maximum efficiency (\%) & 97.0 & 97.0 & 98.0 \\
Weighted efficiency (EURO/CEC) (\%) & 96.4 & 96.4 & 97.5 \\
Night tare (W) & 0.4 & 0.4 & 3 \\
\hline
\end{tabular}

both electric requirements of the EHP and the end user (lights, PCs, etc.). The system is grid connected and interacts in bidirectional way with external grid. Three configurations based on PV plant were considered:

- PV-EHP: electric energy demand is directly covered by the $\mathrm{PV}$ plant and the electric grid;

- $P V$-EHP/BAT: electric energy demand is covered by the $\mathrm{PV}$ plant, the electric battery (BAT), charged by $\mathrm{PV}$, and the electric grid;

- PV-EHP/EV: with respect to the first configuration (PV-EHP) a further electric demand is added considering an electric vehicle. The introduction of electric storage and an EV could lead to a reduction electricity exported to the national grid limiting the problems due to the bidirectional interaction with small scale renewable-based distributed power systems.

The conventional energy conversion system (CS, conventional system) is based on:

- a non-condensing natural gas-fired boiler (B) in heating period with a nominal power of $24.0 \mathrm{~kW}$ and a thermal efficiency, $n_{t h}^{B}$, of $90.2 \%$ (LHV: $9.52 \mathrm{kWh} / \mathrm{Sm}^{3}$ );

- an electric-driven chiller $(\mathrm{CH})$, with a nominal cooling capacity of $13.3 \mathrm{~kW}$ and an EER (energy efficiency ratio) equal to 3.0 ;

- the national electric grid that satisfies electric demand of the user (chiller, lighting, small power equipment, etc.). It was considered the average Italian electric grid efficiency $\left(n_{e l}^{P P}\right)$ that includes: the contribution of the thermo-electric power plants and the renewable energy conversion systems and also transmission and distribution grid losses. Primary energy input takes into account only the contribution of fossil fuel considering null that one of renewable systems. The average electric grid efficiency is considered equal to $65.5 \%$ [18];

- a compact class (C-segment) diesel vehicle characterized by a fuel consumption of $0.032 \mathrm{l} / \mathrm{km}$ (fuel density: $0.833 \mathrm{~kg} / \mathrm{l}, \mathrm{LHV}: 9.88 \mathrm{kWh} / \mathrm{l})$.

In all the considered configurations, the PV panels face south. Furthermore the analysis was carried out considering three different peak powers $(4.5,6.0,7.5 \mathrm{~kW})$. The main characteristic of PV panels are reported in Table 2 . In Table 3 the inverter characteristics, considered for different peak powers, are shown.

The main data of the reversible air to water heat pump are reported in Table 4 . The EHP provides a nominal heating power of $14.1 \mathrm{~kW}$ with a nominal COP (coefficient of performance) of 3.19 , while rated cooling power is $13.3 \mathrm{~kW}$ with an EER of 3.32 .

For the second configuration (PV-EHP/BAT) a Li-ion battery with a capacity of $9.6 \mathrm{kWh}$, a depth of discharge equal to $90.0 \%$ and an efficiency equal to $94.0 \%$ is considered. For the third configuration (PV-EHP/EV) a DCC charging station serving EV is introduced. This technology allows to charge EV battery delivering DC electricity through a DC/ DC converter connected to PV plant. DC fast charging station delivering up to $25 \mathrm{~kW}$ can feed the EV car 60 min before leaving the office to guarantee its full charge. The efficiency of charging system, defined as the ratio between DC power usage of the EV and DC power requirement of the charging station, is $94.0 \%$. The EV considered has a nominal electric storage of $30 \mathrm{kWh}$, with a specific consumption of $0.173 \mathrm{kWh}$ of DC electricity per $\mathrm{km}[20]$. 
Table 4. Air to water heat pump data. ${ }^{a}$

\begin{tabular}{lclr}
\hline \multicolumn{1}{c}{ Heating mode } & \multicolumn{1}{c}{ Cooling mode } \\
\hline Heating power $(\mathrm{kW})$ & 14.1 & Cooling power $(\mathrm{kW})$ & 13.3 \\
Electric power input $(\mathrm{kW})$ & 4.42 & Electric power input $(\mathrm{kW})$ & 4.12 \\
COP $(-)$ & 3.19 & EER $(-)$ & 3.32 \\
\hline
\end{tabular}

${ }^{a}$ Nominal data on the basis of EN 14511:2013 [19].

Table 5. Annual electric energy requirements of the end user.

\begin{tabular}{lccc}
\hline Electric energy per year & PV-EHP & PV-EHP/BAT & PV-EHP $/$ EV \\
\hline Small power office equipments (MWh) & 5.93 & 5.93 & 5.93 \\
Lighting (MWh) & 2.35 & 2.35 & 2.35 \\
EHP (MWh) & 2.40 & 2.40 & 2.40 \\
HVAC auxiliaries (MWh) & 0.79 & 0.79 & 0.79 \\
EV (MWh) & 0.00 & 0.00 & 6.00 \\
Total (MWh) & 11.5 & 11.5 & 17.5 \\
\hline
\end{tabular}

\section{Model description}

TRNSYS is the software considered for the analysis of conventional and proposed systems [21]. It is a common used software to perform dynamic simulations of energy conversion systems used to satisfy energy demand of a building. Each element of the simulated system is modelled through subroutines (so-called "types") found in the software libraries [22]. The components can be linked to each other to develop highly structured systems. In the following the models of the main components are briefly analyzed. PV panel are modelled using type 94 [23] that predicts the current-voltage characteristics of a single module on the basis of a "fourparameter" equivalent circuit built considering manufactures' PV data (Tab. 2). Reversible EHP and CH are modelled on the basis of the performance map of the equipment using type 941 and type 655, respectively. Natural gas fired boiler is modelled considering a constant thermal efficiency boiler model by type 6 . Finally the building is simulated by type 56 that models the thermal behavior of a building having different thermal zones. The fan coils are simulated as an air to water heat exchanger through type 928, in which heating and cooling energy is delivered to an air stream from a source liquid stream.

\section{Methodology}

In this paragraph an energy comparison between the solarbased system (proposed system, PS) with a conventional system (CS) is reported. The performance of the solar based system used to meet electric, heating and cooling demands are compared with those of a reference system based on an national electric grid, a natural gas-fired boiler and an electric chiller. A further energy analysis is performed on the proposed system in order to investigate the contribution of PV plant to cover electric demand of the end user aiming to evaluate the self-consumption of electricity as well as the interaction with external grid.

\subsection{Proposed system analysis}

An analysis of electric energy requirements on annual basis considering three different scenarios is reported in Table 5 . Total electric demand increases in EV configuration, while the other contributions depend on small power office equipment, lighting, EHP and HVAC auxiliaries (fan, circulating pumps, etc.).

Considering the best configuration for each peak power, characterized by a tilt angle of $31^{\circ}$, electric efficiency of PV plant is $14.6 \%$ for $4.5-6.0 \mathrm{~kW}$ and $14.7 \%$ for $7.5 \mathrm{~kW}$. Electric energy available from PV is partly used by end user (blue bar) and partly exported to the grid (green bar), while the contribution from electric grid is always present (red bar), Figure 2.

On the basis of electric energy required by end user, including EV charging station, the best configuration is that one characterized by the greatest self-consumption of electricity. One of the main problem related to PV plants is the exported electricity that could lead to problems on electric grid (voltage regulation, power quality, etc.). Different paths are followed to reduce this interaction, such as the introduction of a stationary electric storage located next to PV plant or a mobile one installed inside an EV. Two indexes could be introduced to evaluate the selfconsumption of PV electricity [24]:

$-s$ : ratio between renewable electric energy supplied through PV to the end user, including charging station EV demand, and the total one that it needs;

- $d$ : ratio between renewable electricity delivered through PV to the end user, including EV demand, and global one available from PV system.

In Table 6 the values of these indexes for three configurations are reported.

Renewable electricity covering end-user's demand $(s)$, increases with PV peak power and with the introduction of the electric storage achieving the best result of $65.5 \%$ for $7.5 \mathrm{~kW}$. The fraction of PV electricity self-consumed, with respect to global production $(d)$, decreases with PV size 


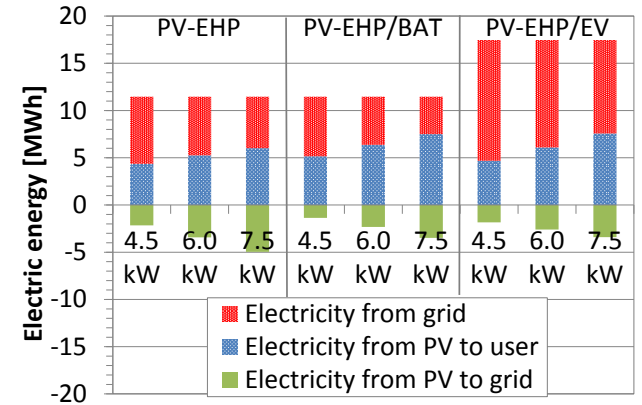

Fig. 2. Electric energy distribution as a function of PV peak power and configuration.

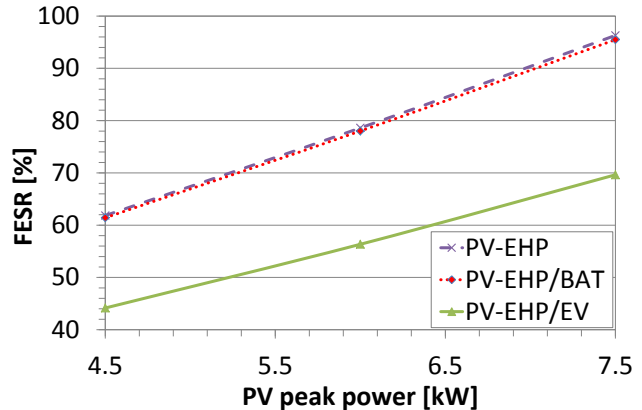

Fig. 3. FESR as a function of $\mathrm{PV}$ peak power and plant configuration.

Table 6. Ratios on the basis of electricity from PV.

\begin{tabular}{llcll}
\hline & PV peak power $(\mathrm{kW})$ & Total electricity from PV $(\mathrm{MWh})$ & $s(\%)$ & $d(\%)$ \\
\hline PV-EHP & 4.5 & 6.52 & 38.0 & 66.9 \\
& 6.0 & 8.69 & 45.9 & 60.5 \\
& 7.5 & 11.0 & 52.5 & 54.8 \\
PV-EHP/BAT & 4.5 & 6.52 & 45.0 & 79.1 \\
& 6.0 & 8.69 & 55.5 & 73.2 \\
& 7.5 & 11.0 & 65.5 & 68.3 \\
PV-EHP/EV & 4.5 & 6.52 & 26.8 & 71.8 \\
& 6.0 & 8.69 & 34.9 & 70.1 \\
& 7.5 & 11.0 & 43.4 & 69.0 \\
\hline
\end{tabular}

while increases with the presence of batteries. The solution characterized by the lower percentage of exported electricity, equal to $20.9 \%(d=79.1 \%)$, is that one obtained for $4.5 \mathrm{~kW}$ and the electricity storage. In the scenario that includes the use of vehicle increasing the size of PV system renewable electricity covering end user demand increases with PV peak power achieving the best result of $43.4 \%$ for $7.5 \mathrm{~kW}$.

\subsection{Energy analysis}

The performance of the analyzed systems have been estimated by means of fuel energy saving ratio (FESR), comparing the primary energy consumption due to fossil fuel of proposed $\left(E_{p}^{P S}\right)$ and conventional $\left(E_{p}^{C S}\right)$ systems. FESR could be defined as (Eq. (1)):

$$
F E S R=\frac{E_{p}^{C S}-E_{p}^{P S}}{E_{p}^{C S}},
$$

where primary energy required by conventional and proposed system is evaluated considering (Eqs. (2) and (3)):

$$
\begin{gathered}
E_{p}^{C S}=E_{p}^{P P}+E_{p}^{B}+E_{p}^{D V}=\frac{E_{e l}^{P P}}{\eta_{e l}^{P P}}+\frac{E_{t h}^{B}}{\eta_{t h}^{B}}+E_{p}^{D V}, \\
E_{p}^{P S}=E_{p}^{P P}-E_{p}^{G r i d}=\frac{E_{e l}^{P P}-E_{e l-e x p}^{G r i d}}{\eta_{e l}^{P P}}
\end{gathered}
$$

where the fossil fuel primary energy demand depends on:
- primary energy $\left(E_{p}^{P P}\right)$ due to electricity drawn from $\left(E_{e l}^{P P}\right)$ and primary energy $\left(E_{p}^{\text {Grid }}\right)$ due to electric energy sent to $\left(E_{\text {el-exp }}^{G r i d}\right)$ the grid. The electricity exported to the grid is considered as a credit for primary energy evaluation of proposed system;

- primary energy input to the boiler $\left(E_{p}^{B}\right)$ needed to satisfy space heating demand $\left(E_{t h}^{B}\right)$;

- primary energy related to the fuel used for traditional car, $E_{p}^{D V}$.

As stated by Figure 3 FESR increases with PV peak power due to the greater availability of renewable electric energy while has a negligible dependence from the introduction of an electricity storage. It ranges between about $62 \%(4.5 \mathrm{~kW})$ and about $96 \%(7.5 \mathrm{~kW})$. Furthermore FESR decreases with EV ranging between $44.1 \%$ and $69.6 \%$. The increase of fossil fuel primary energy demand of conventional system due to the introduction of diesel vehicle leads to worst results in terms of FESR for PV$\mathrm{EHP} / \mathrm{EV}$ configuration.

\section{Conclusions}

A solar electric heating and cooling system, based on a PV plant and an EHP, used to meet electric, space heating and cooling demand of an office building located in southern Italy is here considered. Dynamic simulations to evaluate the energy performance of the proposed system varying PV peak power are carried out. Three configurations (PVEHP, PV-EHP/BAT, PV-EHP/EV) were investigated on 
the basis of the indexes analyzing the self-consumption of electricity and fossil fuel primary energy saving with respect to conventional system. It can be noted that renewable electricity covering end user demand increases with PV peak power while decreases with PV-EHP/EV configuration achieving the best result of $65.5 \%$ for $7.5 \mathrm{~kW}$ for PV-EHP/BAT mode. Considering the fraction of PV electricity self-consumed, with respect to global production, the configuration characterized by the lower percentage of exported electricity, equal to $20.9 \%$ is that one based on PV-EHP/BAT with a peak power of $4.5 \mathrm{~kW}$. In terms of fossil fuel primary energy saving proposed system performs always better than traditional one achieving a FESR up to about $96 \%$ for PV-EHP configuration and $7.5 \mathrm{~kW}$.

\section{References}

1. European Commission, Communication from the Commission to the European Parliament, the Council, the European Economic and Social Committee and the Committee of the Regions on an EU Strategy for Heating and Cooling [Online], 2016, available: https://ec.europa.eu/transparency/regdoc/ $\mathrm{rep} / 1 / 2016 / \mathrm{EN} / 1-2016-51-\mathrm{EN}-\mathrm{F} 1-1 . P D F$

2. GSE Gestore dei Servizi Energetici (Public Authority for Energy Services), Valutazione del potenziale nazionale di applicazione della cogenerazione ad alto rendimento e teleriscaldamento efficiente (Evaluation of the national potential for the application of high-efficiency cogeneration and district heating) [Online, in Italian], 2015, available: http://www.gse.it/it/DatieBilanci/GSE_Documenti/Studi /PotenzialeCAReTLR.pdf

3. I. Sarbu, C. Sebarchievici, Review of solar refrigeration and cooling systems, Energy Build. 67, 286 (2013)

4. G. Angrisani, E. Entchev, C. Roselli, M. Sasso, F. Tariello, W. Yaïci, Dynamic simulation of a solar heating and cooling system for an office building located in Southern Italy, Appl. Therm. Eng. 103, 377 (2016)

5. E. Marrasso, C. Roselli, M. Sasso, F. Tariello, Analysis of a hybrid solar-assisted trigeneration system, Energies 9, 705 (2016)

6. B. Tashtoush, A. Alshare, S. Al-Rifai, Hourly dynamic simulation of solar ejector cooling system using TRNSYS for Jordanian climate, Energy Convers. Manag. 100, 288 (2015)

7. G. Angrisani, C. Roselli, M. Sasso, F. Tariello, G.P. Vanoli, Performance assessment of a solar-assisted desiccant-based air handling unit considering different scenarios, Energies 9, 724 (2016)

8. C.A. Balaras, G. Grossman, H.M. Henning, C.A. Infante Ferreira, E. Podesser, L. Wang, E. Wiemken, Solar air conditioning in Europe - an overview, Renew. Sustain. Energy Rev. 11, 299 (2007)
9. A. de Geus, H. de Beijer, L. Krosse, The SolabCool ${ }^{\circledR}$, cooling of dwellings and small offices by using waste or solar heat, Energy Proc. 70, 23 (2015)

10. IEA (International Energy Agency), Trends 2016 in photovoltaic applications. Report IEA PVPS T1-30:2016, 2016

11. GSE Gestore dei Servizi Energetici (Public Authority for Energy Services), Rapporto statistico 2015 Solare fotovoltaico (Report on PV installations in 2015) [Online, in Italian], 2016, available: www.gse.it/it/DatieBilanci/GSE_Docu menti/osservatoriostatistico/SolareFotovoltaico-RapportoS tatistico202015.pdf

12. C. Roselli, M. Sasso, F. Tariello, Dynamic simulation of a solar electric driven heat pump for an office building located in Southern Italy, Int. J. Heat Technol. 34, S496 (2016)

13. N. Hartmann, C. Glueck, F.P. Schmidt, Solar cooling for small office buildings: comparison of solar thermal and photovoltaic options for two different European climates, Renew. Energy 36, 1329 (2011)

14. C. Roselli, M. Sasso, F. Tariello, Dynamic simulation of a solar electric driven heat pump integrated with an electric storage for an office building located in Southern Italy, Int. J. Heat Technol. 34, 637 (2016)

15. M. Izquierdo, P. de Agustín, E. Martín, A micro photovoltaic-heat pump system for house heating by radiant floor: some experimental results, Energy Proc. 48, 865 (2014)

16. C. Roselli, M. Sasso, Integration between electric vehicle charging and PV system to increase self-consumption of an office application, Energy Conver. Manag. 130, 130 (2016)

17. A.C. Menezes, A. Cripps, R.A. Buswell, J. Wright, D. Bouchlaghem, Estimating the energy consumption and power demand of small power equipment in office buildings, Energy Build. 75, 199 (2014)

18. Terna, Statistics and forecasts, Statistical data, Production [Online, in Italian], 2013, available: https://www.terna.it/ en-gb/sistemaelettrico/statisticaldata.aspx

19. EN 14511:2013, Parts 1-4 Air conditioners, liquid chilling packages and heat pumps with electrically driven compressors for space heating and cooling, 2013

20. H. Ribberink, E. Entchev, Exploring the potential synergy between micro-cogeneration and electric vehicle charging, Appl. Therm. Eng. 71, 677 (2014)

21. TRNSYS v. 17.01.0025, TRaNsient SYstem Simulation Program (Solar Energy Laboratory, University of Wisconsin-Madison, USA, 2010)

22. TESS, Component Libraries v.17.01 for TRNSYS v17.0 and the TRNSYS Simulation Studio Parameter/Input/Output Reference Manual (Thermal Energy System Specialists, LLC, 2004)

23. D. Mazzeo, N. Matera, P. Bevilacqua, N. Arcuri, Energy and economic analysis of solar photovoltaic plants located at the University of Calabria, Int. J. Heat Technol. 33, 41 (2015)

24. J. Weniger, T. Tjaden, V. Quaschning, Sizing and grid integration of residential PV battery systems, Energy Proc. 46, 78 (2014)

Cite this article as: Carlo Roselli, Maurizio Sasso, Francesco Tariello, Integration between electric heat pump and PV system to increase self-consumption of an office application, Renew. Energy Environ. Sustain. 2, 28 (2017) 